\title{
CXCL10 and neopterin in CSF are candidate prognostic biomarkers for HTLV-1-associated myelopathy/tropical spastic paraparesis
}

\author{
Yoshihisa Yamano ${ }^{1 *}$, Tomoo Sato ${ }^{1}$, Hitoshi Ando ${ }^{1}$, Natsumi Araya ${ }^{1}$, Naoko Yagishita', Junji Yamauchi ${ }^{1}$,
} Ariella Coler-Reilly', Atae Utsunomiya ${ }^{2}$, Steven Jacobson ${ }^{3}$, Shuji Izumo ${ }^{4}$

From 16th International Conference on Human Retroviruses: HTLV and Related Viruses Montreal, Canada. 26-30 June 2013

Human T-lymphotropic virus type 1 (HTLV-1) -associated myelopathy/tropical spastic paraparesis (HAM/TSP) is a chronic neuroinflammatory disease. Since the disease course of HAM/TSP varies among patients, there is a dire need for biomarkers capable of predicting the rate of disease progression for earlier detection of high-risk patients. However, there have been no studies to date that have compared the prognostic values of multiple potential biomarkers for HAM/TSP. Peripheral blood and cerebrospinal fluid (CSF) samples from HAM/TSP patients and HTLV-1-infected control subjects were obtained and tested for several potential biomarkers, including chemokines and other cytokines, and 8 optimal candidates were selected based on receiver operating characteristic (ROC) analysis. Next, we evaluated the relationship between these candidates and the rate of disease progression in HAM/ TSP patients, beginning with a Training Set of 30 patients and proceeding to a Test Set of 23 patients. We defined "deteriorating HAM/TSP" as distinctly worsening function ( $\geq 3$ grades on Osame's Motor Disability Score (OMDS)) over 4 y and "stable HAM/TSP" as unchanged or only slightly worsened function (1 grade on OMDS) over $4 \mathrm{y}$, and we compared the levels of the candidate biomarkers in patients divided into these 2 groups. The CSF levels of chemokine (C-X-C motif) ligand 10 (CXCL10), neopterin and the CSF cell count were well-correlated with disease progression, better even than HTLV-1 proviral load in PBMCs. Importantly, these results were cross-validated using the Test Set. Therefore, the CSF levels of CXCL10

\footnotetext{
* Correspondence: yyamano@marianna-u.ac.jp

${ }^{1}$ Institute of Medical Science, St. Marianna University School of Medicine, Kawasaki, Japan

Full list of author information is available at the end of the article
}

and neopterin represent the most viable candidates for HAM/TSP prognostic biomarkers.

\section{Authors' details}

${ }^{1}$ Institute of Medical Science, St. Marianna University School of Medicine, Kawasaki, Japan. ${ }^{2}$ Department of Hematology, Imamura Bun-in Hospital, Kagoshima, Japan. ${ }^{3}$ Viral Immunology Section, Neuroimmunology Branch, National Institutes of Health, Bethesda, MD, USA. ${ }^{4}$ Molecular Pathology, Center for Chronic Viral Diseases, Kagoshima University, Kagoshima, Japan.

Published: 7 January 2014

\section{doi:10.1186/1742-4690-11-S1-P18}

Cite this article as: Yamano et al.: CXCL10 and neopterin in CSF are candidate prognostic biomarkers for HTLV-1-associated myelopathy/ tropical spastic paraparesis. Retrovirology 2014 11(Suppl 1):P18.
Submit your next manuscript to BioMed Central and take full advantage of:

- Convenient online submission

- Thorough peer review

- No space constraints or color figure charges

- Immediate publication on acceptance

- Inclusion in PubMed, CAS, Scopus and Google Scholar

- Research which is freely available for redistribution

Submit your manuscript at www.biomedcentral.com/submit
C Biomed Central 